\title{
Participants' Knowledge about Exchange Traded Funds: An Evidence from Karachi Stock Exchange
}

\author{
Arshad Khan ${ }^{1}$ \\ Syed Farhan Shakeel ${ }^{2}$
}

\begin{abstract}
This study investigates and highlights the factors differentiating professional investors from retail investors, causing overall deficiency in overall investors' knowledge about Exchange Traded Funds at Karachi Stock Exchange. Participants to the study are Authorized Participants, including brokers listed under the regulations of Karachi Stock Exchange Guarantee Ltd. Currently, out of 200 listed brokers $50 \%$ were conveniently selected as participants to this study. Likert scaled questionnaires were floated to have their responses. Mean response to all examined variables was more than 3 which lead us to the understanding that all participants were somehow agreed that there exist knowledge deficiency in Pakistan's ETFs market. Among all factors ranging from SECP Regulations, KSE Regulations to Trading Strategies, on average the factor, Trading Strategies with highest mean response of 3.34 indicated that respondents were more confident about deficiency of knowledge in Trading Strategies at KSE and Authorized Participants or investors at KSE has to consistently develop and improve the existing level of knowledge. Participants' consistency levels about knowledge deficiencies in all variables (i.e. overall investors' knowledge, SECP Regulations, KSE Regulations and Trading Strategies) have 10.53\%, 10.37\%, $13.21 \%$ and $15.56 \%$ coefficients of variations respectively. This shows that participants' responses were more consistent about the deficiency in understanding SECP regulations followed by investors' overall knowledge. Spearman's Correlation coefficient for all independent variables at 5\% significance level with P-value $<0.5$ were (knowledge deficiency in SECP Regulations $r=0.547$, deficiency in KSE Regulation $r=0.533$, knowledge deficiency in understanding ETFs Trading Strategies with $r=0.536$ ) found statistically significant. Hypotheses for significance influence of independent variable on dependent variable were also tested to support the findings.
\end{abstract}

Keywords: Authorized participants, knowledge, exchange traded funds, KSE, SECP

\section{Introduction}

\subsection{Background of the Study}

Being one of the most innovative financial products, bearing like low cost, liquidity, tax efficiency, close index tracking quality characteristics and transparency in nature, Exchange Traded Funds (ETFs) has been most attractive product for two decades. In early 1990s, ETFs were introduced in the US and Canadian markets with the small fraction of growth. According to Pauline and Jisok (2013) the importance and exponential growth of ETFs triggered investors in 1993 when it was first listed and successfully traded in SPDRs (Standard \& Poor's Depositary Receipts). Currently, ETF industry held \$2 trillion in assets across more than 1442 exchange traded products (Stoyu, 2013). In United States, overall ETFs assets worth is about $\$ 296.02$ billion, compared to $\$ 8.9$ trillion assets in mutual funds. Ishare (2013) reports indicated that they are managing more than 500 active ETFs having more than US\$670 billion

${ }^{1}$ Arshad Khan is Deputy Manager Finance, United Marine Agencies (Pvt.) Limited, Karachi, arshadkhpk@ gmail.com ${ }^{2}$ Syed Farhan Shakeel is Assistant Professor, Management Sciences, SZABIST, Karachi, syed.farhanshakeel@ szabist.edu.pk \begin{tabular}{llll|l}
\hline JISR-MSSE & Volume 11 & Number 1 & Jaunary - June 2013 & 67
\end{tabular} 
assets. Exchange Traded Funds have also extended from equities to international market commodities, and fixed income instruments like Bonds.

Despite of this tremendous growth and unanimous market penetration the developmental phase of ETFs has dealt with major issue of investors' knowledge about this product. It is the objective and charter of ETFs governing body to ensure the accurate and prudent NAV (Net Asset Value) disclosure to general public. ETFs markets operate round the clock therefore, at the end of every trading session every exchange commission ensures the accuracy of NAV. Initially, it was considered that only having valuation and investment expertise in ETFs makes an investment professional proficient. Up to year, 2000 the knowledge sphere was limited to the relevant proficiency that is expertise in ETF Trading Strategies. In early 2001, financial experts attention was triggered by MSCI NAV where not only tax laws but SEC (Security and Exchange Commission) regulations coupled with Exchange Regulations effected the valuation of ETF. Thus the investors' knowledge sphere was extended from ETF Trading Strategies to Exchange Regulations and SEC regulations. It has become mandatory for every fund manager to have more knowledge of relevant territorial law along with Trading Strategies. Even, international institutions who are inculcating finance knowledge included the knowledge and adherence to strict law in their code of ethics and standards of professional conduct.

On March 5, 2012 SECP (Security and Exchange Commission of Pakistan) in her initial press release formally allowed and regulated listing of ETFs at KSE (Karachi Stock Exchange). The released regulations empowered the KSE to list and regulate the process, creation and ETFs trading in portfolio of diversified securities. SECP regulations covered procedures for listing ETFs, settlement of ETFs units, their trading, clearing and disclosure requirements for AMC (Asset Management Companies), obligations of authorized participants, their fee structure etc. On the other hand, KSE's regulations covered different aspects of Authorized Participants' activities only. On May 8, 2012 SECP in its press release disclosed compact set of regulations for launching ETFs on KSE by AMCs (Asset Management Companies). "Circular 15 of 2012" by SECP stipulated the regulatory requirements for the ETFs which included role of Authorized participants, investment restrictions, expenses and fee, pricing and dealing additional disclosure requirements and issuance and redemption of creation units. Beside all above regulations, the existing level of investors' knowledge remained untapped by regulators. As discussed earlier international proficiency in ETFs knowledge span has been extended from its trading strategies to territorial regulations. In the context of Pakistan, the question arises, whether existing level of knowledge in investor meets the optimum level of knowledge, required for efficient and effective ETF trader? If this deficiency exists, then which factor is most influencing? How much these factors individually and aggregately affect the overall investors' knowledge?

The significance and importance of having knowledge about SECP regulations, KSE regulations and ETFs trading strategies can be well assessed once we go through the launching, creation, trading and processing phases of ETFs with parallel involvement and obligations to regulators for the integrity of investor and ETFs market. Since, share on ETFs can only be bought or sold on exchange. Before an ETF launch an institutional investor called Authorized Participant must create the seed capital. Like in following structure Authorized Participants must commit Rs.100 million to create 1 million shares. Authorized Participants makes the stock basket which keenly track particular benchmark index in return ETF sponsors (Asset Management Companies) create and issue equal value of ETF shares to Authorized Participant for one for 
one trade. Authorized Participants sells the ETF share in open market on continuous bases. If Authorized Participant sees more demand in market he buys more shares from the market makes basket and gets equal value of ETF shares and sells it in open market. If demand in market is low then Authorized Participants returns ETF shares to ETF sponsors and sells that basket in open market. Process shows that an ETF works differently, if an investor wants to buy an ETF he has to enter to the buyer account with brokers just like do with regular stock. Investor can place his or her order either at market price or at desirable price or at particular limit price. Broker then goes to the market (Stock Exchange) and find someone selling those shares. They complete that transaction for investor and deliver same stock to the investors against equivalent amount of money along with brokerage to the broker. It is the arbitrage profit which will induce an authorized participant to create and redeem ETF shares regularly. Graphically, crux of ETF process can be presented as under:

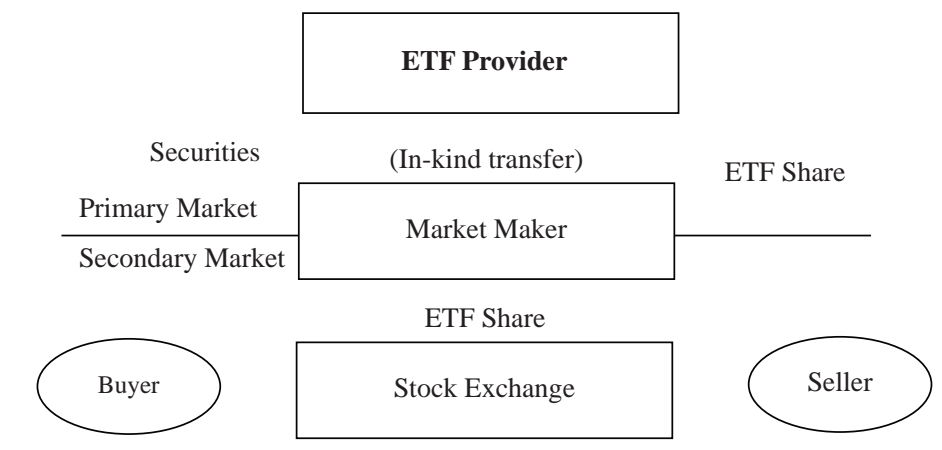

Source: Index Universe ETF, 2012.

Starting from seeding capital, designing portfolio that perfectly tracks bench mark index, buyer account with broker, order placement at market price, desirable price and particular limit price, execution at stock exchange, brokerage payments and controlled arbitrage profits all these will determine the true NAV. Investor knowledge framework plays a vital role for proper and unbiased execution of ETFs process. This is obvious from flow of process that ETF knowledge framework is comprised of having expertise in Trading Strategies, Stock Exchange Regulations and SEC Regulations.

\subsection{Problem Statement}

Being new innovative pool of investment, Exchange Traded Funds' legal and functional structure need competent authorized participants/ investors to establish and develop efficient ETFs market on contemporary practices and professional standards rather being retail investors.

\subsection{Research Objectives}

The core objectives of the study are:

- To discover the deficiency in existing level of investors' knowledge framework.

- To determine individual and joint intensity of identified variables in ETF knowledge framework.

\begin{tabular}{lll|l}
\hline JISR-MSSE & Volume 11 & Number 1 & Jaunary - June 2013 \\
\hline
\end{tabular}




\subsection{Research Questions}

Following core questions are raised in this study:

- Whether level of knowledge which distinguishes retail investors from professional investor exists in KSE participants to maintain the ETFs' Low Cost, Liquidity, Diversification and Transparency characteristics along with efficient market?

- How far the element of ETF knowledge framework influence the ETF market in Pakistan?

\subsection{Scope of study}

This study explores and analyzes the deficiency in required level of investors' knowledge and the potential of deficiency which need preemptive and corrective measures from all stakeholders. Geographically, this study covers the Pakistan ETF market where as thematic scope of this study is the area of alternate investments in finance.

\subsection{Delimitations}

Initially, questionnaire was floated to target population of 200 listed brokers but due to their time and interest concerns, they were reluctant to answer or felt it as secrecy disclosure. Many of the responses were illegible eventually; method of convenient sampling was adopted to conduct the research.

\section{Research Methodology and Design}

Being new investment paradigm for Pakistani investors, brokerage houses / members who are listed at Karachi Stock Exchange and vis- a- vis who can be appointed as authorized participants, were included as target participant to this research. Out of 200 listed brokerage houses, 100 (i.e. $50 \%$ of the population) were approached conveniently through five point Likert scale questionnaire containing 20 questions. Likert scale was ranging from strongly disagree to strongly agree (1. Strongly Disagree, 2. Disagree, 3. Neutral, 4. Agree and 5. Strongly Agree). The responses were analyzed through SPSS16 and Excel worksheet.

\subsection{Research Hypotheses}

Based upon literature following hypotheses were formulated:

H1: Deficiency in understanding SECP regulations has no significant impact on investors' knowledge.

H2: Deficiency in understanding KSE regulations has no significant impact on investors' knowledge.

H3: Deficiency in understanding ETFs trading strategies has no significant impact on investors' knowledge.

H4: Investors knowledge is not affected by understanding deficiency about SECP regulations, KSE regulations and ETFs Trading Strategies.

\begin{tabular}{l|llll}
\hline 70 & Jaunary - June 2013 & Volume 11 & Number 1
\end{tabular} 


\section{Literature Review}

Since August, 2002 Wall Street has been focusing ETFs as fastest growing and emerging financial innovation. ETFs have attracted researchers' attention in every dimension where it can affect the investors' stake. In last decade, ETFs have been compared with financial products like Mutual Funds (close ended and opened) and have also been worked out broadly on their quantitative and qualitative aspects by researchers and institutions. Some researchers have identified the quantitative edge of ETFs over other financial products while some of the researchers have discussed the shortcomings of ETFs. Literature review of this research starts with the researchers' general views about ETFs to the specific views on investors' knowledge about ETFs.

An argument was passed by (Dellva, 2001) described the shortcomings that ETFs are not for everyone. He was of the view that ETF paradigm is the conjunction of multiple regulatory frameworks. Strauss \& Stuart, (2000) and of the same opinion that complexities of ETFs are much higher which can affect the future growth therefore enhancement in existing level of investors' capabilities is essential. He further added that mutual fund or ETFs pay redeeming shareholders cash for their share and eventually time comes where investors are forced to sell the securities to release the obligations of those payments. He further added that fund manager proactive response can give edge to ETFs management and competency of participants or market makers must be distinguished from retail investors.

While emphasizing on the participants' competency to manage and take informed decision (Vanguard, 2012) issued ETFs advisor guide for Investment professional. According to them, management of ETFs is the task of professional authorized participants rather than retail investors or participants. Authorized participants with the capabilities to carry out funds management by deploying low cost, liquidity, diversification and transparency strategies are the professional investors. Advisors' guide also stressed on the determination of clients' suitability to Exchange Traded Funds.

Clients' suitability to ETFs and professional competancy was determined by (BlackRock,2011) and came up with the major distinguishing factors. These factors included, clients' investment policy statement, the size of clients' portfolio with the quantum of trasaction in it, the time horizons for which investment is going to be made, trading strategies of brokers, level of diversification in ETFs basket, Cost saving applications, portfolio rebanling and taxation management of client portfolio. Report further aruged for the development of new ETFs market authorized participants must posses broader level of horizental knowledge.

\subsection{Security and Exchange Commission of Pakistan Regulations}

Department of specialized companies division, regulation, policy and development issued a comprehensive framework for ETFs on eight day of May, 2012. More obligations in addition to NBFC Rules, 2003 and NBFC and notified entities Rules 2008 were laid down to introduce the framework of exchange traded funds.

Governing document defined ETFs as “ Listed Index-Tracking Open End Fund structured as collective investment scheme whose primanry objective is to mimic the return of a particular benchmark index by investing substantally all of its assets in the constituent securities of the

\begin{tabular}{llll|l}
\hline JISR-MSSE & Volume 11 & Number 1 & Jaunary - June 2013 & 71
\end{tabular}


benchmark index. ETF shall issue and redeem Creation Units in-kind through Authorized Participants only." Authorized Participants was made intermediator to transact on behalf of actual investor. The role of Authorized Participant is expected to be an expert in trading duly authorized by investor agent. Therefore, he/she must have overall knowledge of ETF trading along with existing regulatory framework.

\subsubsection{Disclosure Requirement}

(SECP, 2013) Investor of ETF must know and understand the offering document disclosures. These disclosures are not only limited to ordinary disclosures of a collective Investment Schemes prescribed in regulation but it must contain additional disclosures to the ETF as described in Annxure "B" of the SECP circular 15 of 2012. Investors must know, an approved ETF must have clearly defined objective, it must reflect the charactristics of the relevent sector, composition, change and weightings of the component securities and most importantly one component security will not exceed $20 \%$ of the total value of the ETF. ETF must be based on securities listed and traded on stock exchanges of Pakistan. Asset Mangement Companies are held resposible to publish and carry out consistantly all the requirement mentioned above. They are also responsible to inform any difficiancy in ETFs to SECP. In contrast to these regulation, (Gauhar, 2013) in their Business Maganize reported that keeping popularity of ETFs, It has become essential for every authorized participant to adhere with SECP regulations so that they can take informed decision while managing ETFs.

\subsubsection{Investment Restrictions}

As per regulations (SECP, 2013) in addition to some exceptions, not more than $15 \%$ deviation from benchmark index is acceptable to SECP. Asset Management Companies are responsible to remain $85 \%$ invested in the component of the securities of the benchmark index and rest could be comprised of cash or cash equivalent. In relation to security held by ETF Asset Management Company must ensure per-party, per group and sector exposure limits in accordance with weightage in benchmark index. Any deviation must be rectified within three business days. Asset Management Company can itself be authorized participant for ETFs. It is his/her obligation to remain in prescribed margin limits by SECP. If an authorized participant does not exercise this limit he/she will be in voilation of legal requirement hence, the performance of ETFs will be at stake.

\subsubsection{Issuance and Redemption of Creation Units}

Fonder, (2013), SECP regulations seem more complex in nature this may also question the free movement of demand and supply forces in ETFs market. As, Authorized Participants' Agreement covers detailed procedure for the issuance and redemption of creation units this copy must be submitted to SECP. It has been mandatory that all the requests are to be made through Authorized Participants. AMC (Asset Management Company) may change the size of Creation Unit only if it is permitted by Authorized Participants' Agreement. AMC within three working days will be further liable to take prior approval for "Change" from the trustee and SECP. It is the responsibility of AMC to make more clear and concise procedures and provisions in Constitutive Documents. Trustee can also issue or redeem Creation Units only upon the instruction of AMC with the compliance of NBFC Rules and Regulations.

\begin{tabular}{l|llll}
\hline 72 & Jaunary - June 2013 & Volume 11 & Number 1
\end{tabular} 


\subsubsection{Pricing, Dealing and Public Information}

(SECP, 2013) AMC in the context of Constitutive Documents will issue or redeem and ensure Creation units at NAV whose units trade on Stock Exchange. AMC shall also ensure INAV per unit and the end of the day NAV per unit. Third Party is also given right to ensure the valuations objectively and independently. AMC will also ensure that the ETF has at least one Authorized Participant who will be appointed by the AMC for the purpose of In-kind issuance and In-kind redemption of Creation units with ETF under the APA and for active market making in ETF. It is important to note that creation of unit at NAV possible only when investor is well versed at existing regulations or there is no regulatory framework for investor.

\subsection{Karachi Stock Exchange Regulations}

\subsubsection{Trading Clearing and Settlement of ETF Unit}

In addition to the regulations governing risk management, ETFs trading must be governed under the exchange regulation amended time to time (KSE, 2013). Under the KSE regulations, units of ETFs will be traded in the ready market through KATS. Requirement of Netting, exposure, mark to market, circuit breakers and other margins are applicable. This requires full understanding of investors to ready market and KATS. Investors must also understand the concepts of Netting on and off the market, exposure, circuit breakers and required margins in special context of Karachi Stock Regulations for ETFs.

On September 19, 2011 Deutsche Bank launched new fund with the name "db x-trackers MSCI Pakistan IM TRN" in American US dollar. Total fund asset on 31 July, 2012 were USD 6,992,400/- with its corresponding NAV of USD1.17. On 31 July, 2013 this fund was comprised of $\mathrm{OGDCL}=21.86 \%, \mathrm{MCB}=15.69 \%, \mathrm{FFCL}=13.59 \%, \mathrm{POL}=5.59 \%, \mathrm{UBL}=5.47 \%$, $\mathrm{ENGRO}=4.48 \%, \mathrm{LUCK}=4.46 \%, \mathrm{NBP}=4.28 \%, \mathrm{PPL}=3.62 \%$ and $\mathrm{HABCO} 3.06 \%$ holdings Pointing the regulatory weaknesses, (Deutsche bank, 2012) further reported that ETF is not capital guaranteed or protected so investors might not get back their investments. Risk at the maximum rate of $10 \%$ derivative counterparty ETFs may be exposed to counter-party risk. Furthermore, the annual management fee may not make able the comparison of returns achieved by direct investments. In such situations, regulation governing Exchange carry weight over trading strategies.

Ziglar (2002), in his article "ETFs Finish in First Place”, focused on the benefits of ETFs over conventional mutual funds. According to him, ETFs structure is open ended having dual pricing bid-offer spreads, linked with NAV (Net Asset Value). He further added that it is the arbitrageur who keeps the prices very closed to the NAV therefore; participants must be well versed in exchange regulations of ETFs.

Rizvi (2013) argued that about 35\% of the existing funds managers are not well equip with basic investment tools, asset valuation tools, and exchange regulations. Participants overall knowledge will ensure the effective management of new financial products sepcially Exchange Traded funds. He was also of the view that they should understand complete cost structure laid down by exchanges.

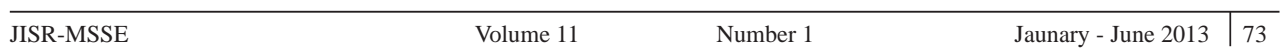




\subsubsection{Obligation of Authorized Participants and Annual Cost Structure}

Authorized Participants must comply with market making agreement and authorized participants' agreement. Listing fee maximum of five hundered thousand is to be paid by AMC to the exchange. AMC would also pay annully according to the Size of Fund givenbelow;

\begin{tabular}{|c|c|}
\hline Size of Fund & Rate of Fee per anum (Rs.) \\
\hline Less than or equal to Rs. $150 \mathrm{ml}$ & 30,00 \\
\hline Exceeding $150 \mathrm{ml}$ and less than or equal to $500 \mathrm{ml}$ & 40,000 \\
\hline More than $500 \mathrm{ml}$ & 50,000 \\
\hline
\end{tabular}

Source: KSE, 2013. Regulations Govering Market Makers

Besides, AMC will also have to pay non-refundable charges of Rs.25,000 for enlisment of fund.

\subsection{ETF Trading Strategies}

To obtain potential benefits like low costs, liquidity and transparancy of ETFs researchers have emphisized on the importance of strategies underlysing ETFs. Accroding to Goetzmann, (2001), it is obvious ETFs costs are on average less than convential mutual funds. It is important to understand full 'in all' investing cost in ETFs to check the suitability for client or portfolio. ETFs also folds the cost of trading on stock markets, including brokerage commissionand bid offer spreads.

Mark and Roberto (2011) focused the ability of Authorized Participants' ability for creation and redemption of Creation Unit, trading throughout the day. They also stressed the creation of market basket for the maximum of market representative.

Jeeman (2005), in his paper "Samuelson's Dictum and the Stock Market for ETFs" says Authorized Participants must understand his client's risk profile and investment objective. Clients Suitability to ETFs must be determined by keeping in practice the following points:

- Whether the client wishes to invest regularly or want to invest the lump sum amount of money

- Expected and projected size of clients' portfolio with its corresponding transaction amount

- The span of time for investment client is opt for

Bruce, Greig and Martin (2011) said trading flexibility is a key benefit of ETFs but it does not suit all investors. Averaging pound cost with regular trasactions also give benefit to investors. 
Accoding to Ananth (2012), ETFs offer a diversified investment, tracking all or a sample of the companies, geographies or elements of the index it tracks. Some ETFs hold thousands of stock and a single investment can diversify an investor's porfolio instantly. This diversification can help to reduce the manager and individual security risk in clients' portfolio. Total management costs reduction in ETFs is a potential solution. One of the largest hidden cost for investor is restructuing cost of restructuring portfolio. Strategic asset allocation that meet the objective of client is very important for the success of investment strategy. Value of asset over the period of time change without rebalancing the i nvestors' portfolio jeoperdises eventually, reduces the objectivity of client portfolio. According to Gary (2003), client of Authorized Participants should not experience the drastic change in taxation. Realized capital gains tax allowance, while income they receive should be taxed as income.

\subsection{Theme of the Research}

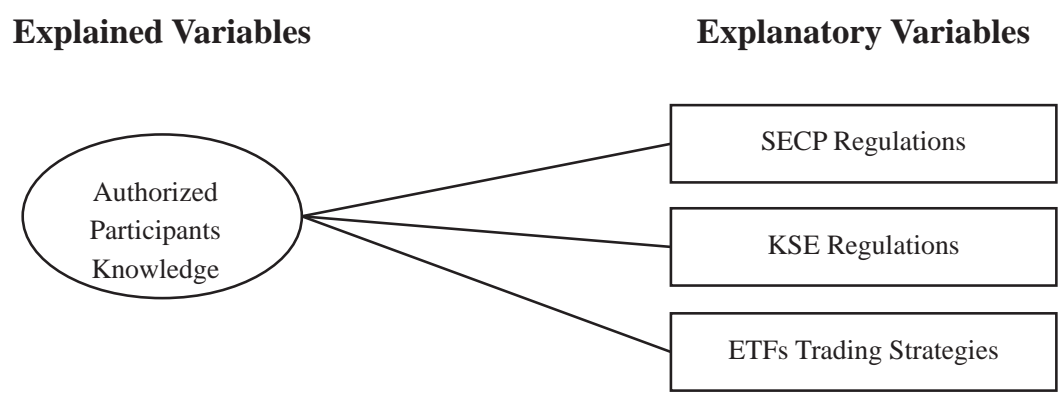

Source: Insights from (Vanguard, 2012) and modified in local context

\section{Data Analysis and Findings}

Data Analyses start from checking Cornbach's Alpha reliability test of the questionnaire followed descriptive and inferential analyses to interpret the significant findings. Mean, Median, Mode, Standard Deviation, Variance and Coefficients of Variations, Correlation along with simple and multiple regressions and hypothesis testing were carried out. Refer to Table 1 , in list of annexures, overall reliability of data is $85 \%$ since, acceptable to conduct the study within its scope. $85 \%$ Cronbach's reliability shows acceptable and reliable consistency among independent and dependent variables for research.

\subsection{Descriptive Analysis}

Table 2 indicates mean response, that is deficiency in understanding SECP regulations governing ETFs is 3.29 (agree stance ) with the standard deviation of $34.17 \%$ and variance of $11.67 \%$, mean response for deficiency in understanding KSE regulations that govern ETFs is 3.30 with standard deviation of $43.53 \%$ and variance of $18.95 \%$. On the other hand, deficiency in understanding ETFs trading strategies has mean response of 3.34 with standard deviation of $51.93 \%$ and variance of $26.97 \%$. It is important to note that all identified factors 
determine on average "Agree" response from participants that there is knowledge deficiency about ETFs among investors. This also led us to the understanding of relative importance of identified factors. Having focus on mean responses only, among all factors, (SECP regulations, KSE regulations and Trading Strategies) on average the factor of Trading Strategies with the mean response of 3.34 moving towards "Agree" means more expose to attention that authorized participants or investors KSE have to develop their current level knowledge. This study does not generalize findings on the bases of mean responses. For the purpose of more advanced and empirical generalization scope of analyses has been expended to other useful statistical techniques and methods.

To have more insight in descriptive analyses coefficient of variation is computed to check the respondents' consistency towards each explanatory variable. Deficiencies in investors' knowledge, SECP regulations, KSE regulations and Trading Strategies have 10.53\%, 10.37\%, $13.21 \%$ and $15.56 \%$ coefficients of variation respectively. Analyses further revealed that deficiency in understanding of SECP Regulations has lesser coefficient of variation which means that respondents are more consistent about the knowledge deficiency of SECP regulations. Hence, it can be concluded that among all independent variables SECP regulations need to be understood by investors.

\subsection{Distribution}

To check the deviation from normal population skewness in Table 3 is computed. In analyses Skweness for deficiency in Investors' Knowledge, KSE regulations and ETFs Trading Strategies are 1.91, 2.23 and 2.27 respectively. This means that most of the responses are left centered to the mean with extreme value to the right. Since we can conclude that distribution for Investors' knowledge, KSE Regulations and Trading Strategies are right skewed. On the other hand, Skewness for SECP Regulations 0.88 means, most of the responses are right centered to the mean with extreme value to the left. Since, it can be concluded that distribution is left skewed.

To check the distribution Flatness or Peakness, Kurtosis was calculated. Kurtosis values for deficiency in Investors' Knowledge, KSE Regulations and Trading Strategies are greater than 3. This led to the understanding that distribution is sharper than normal distribution with thicker tails and values centered on the mean. Thus it can be concluded that shape of the distribution is leptokurtic for deficiency in Investors' knowledge, KSE Regulations and Trading Strategies. Kurtosis for SECP Regulation is less than 3 means distribution for SECP regulation is flatter than normal distribution. Thus values are wider spread around the mean hence, distribution is Platykurtic.

\subsection{Analysis of Correlation}

In Table 4 Spearman's correlation coefficient for knowledge deficiency in SECP regulations with $r=0.547$ and $p$ value is less than 0.05 at $5 \%$ significance level was found statistically significant. Deficiency in understanding KSE regulations with $r=0.533$ and $p$ value is less than 0.05 which was also significant at $5 \%$ level of significance. Similiarly, knowledge deficiency in understanding ETFs Trading Strategies with $\mathrm{r}=0.536$ was also significant at $5 \%$ level of significance.

\begin{tabular}{l|llll}
\hline 76 & Jaunary - June 2013 & Volume 11 & Number 1
\end{tabular}




\subsection{Inferential Analysis}

\section{Hypothesis 1}

Deficiency in understanding SECP regulations has no significant impact on investors' knowledge

$\mathrm{H}_{0}: \beta=0, \mathrm{H}_{1}: \beta \neq 0$

Table 5 shows total variation of $\mathrm{R}^{2}=47.90 \%$ in Investors' overall knowledge deficiency is explained by lack of understanding SECP regulations. Holding other things constant, $1 \%$ deficiency in understanding SECP Regulations causes on average $71 \%$ deficiency in overall investors' knowledge. Furthermore, probability value is less than 0.05 (p-value $<0.05$ ) or $\mathrm{t}$-value $(\mathrm{t}=9.596)$ is greater than 2 null hypothesis is rejected as SECP regulations have no significant influence on overall investors' knowledge.

\section{Hypothesis 2}

Deficiency in understanding KSE regulations has no significant impact on investors' knowledge

$\mathrm{H}_{0}: \beta=0, \mathrm{H}_{1}: \beta \neq 0$

According to Table 5 total variation of $\mathrm{R}^{2}=54.40 \%$ in investors' knowledge deficiency is explained by lack of understanding KSE regulations. 1\% understanding deficiency in KSE regulations causes on average $59.30 \%$ deficiency in investors' knowledge, holding other things constant. Furthermore, probability value is less than 0.05 (p-value $<0.05$ ) or t-value ( $\mathrm{t}=10.903)$ is greater than 2 null hypothesis is rejected because KSE Regulations have no significant influence on Investors' Knowledge.

\section{Hypothesis 3}

Deficiency in understanding ETFs trading strategies has no significant impact on investors' knowledge

$\mathrm{H}_{0}: \beta=0, \mathrm{H}_{1}: \beta \neq 0$

Refer to Table 5 total variation of $\mathrm{R}^{2}=65.40 \%$ in investors' knowledge deficiency is explained by lack of understanding ETFs Trading Strategies. Holding other things constant, $1 \%$ deficiency in understanding ETFs Trading Strategies causes on average $54.40 \%$ deficiency in investors' knowledge. Furthermore, probability value is less than 0.05 or t-value is greater than 2 null hypothesis is rejected because ETF Trading Strategies have no significant influence on investors' knowledge. 


\subsection{Multiple Regression Model}

Hypothesis: Investors knowledge is not affected by understanding deficiency about SECP regulations, KSE regulations and ETFs Trading Strategies

$H_{0}: \beta_{1}=\beta_{2}=\beta_{3}=0, H_{1}: \beta_{1} \neq \beta_{2} \neq \beta_{3} \neq 0$

Refer to the Table given below, the probability value is less than 0.05 or t-value is greater than 2 therefore, null hypothesis is rejected as Investors knowledge is not affected by SECP Regulations, KSE Regulations and Trading Strategies.

Table given below also presents Multiple Regression analyses having $\mathrm{R}^{2}=86.20 \%$. That is about $86 \%$ of the variation in deficiency of investors knowledge can be explained by regression on these variables, (SECP regulations, KSE regulations and ETFs Trading Strategies) Following model is generated to predict the value of investors' knowledge from the value of SECP regulations, KSE regulations and ETF Trading Strategies.

Investors' knowledge $=0.216+0.327 \mathrm{SECP}$ Regulations $+0.337 \mathrm{KSE}$ Regulations +0.271 Trading Strategies or shortly; $\quad$ INVKNO $=0.216+0.327 \mathrm{SECP}+0.337 \mathrm{KSE}+0.271 \mathrm{TS}$

The intercept 0.216 is the level of investors' knowledge that would be expected if all three independent variables (SECP Regulations, KSE Regulations and Trading Strategies) were equal to zero. Holding, KSE Regulations and Trading Strategies same, for a marginal increase in understanding deficiency of SECP Regulations, deficiency in investors' knowledge is increases by 0.327 . Holding SECP Regulations, and ETFs Trading Strategies same, for a marginal increase in understanding deficiency of KSE Regulations, deficiency in investors' knowledge is increases by 0.337. Holding SECP Regulations, and KSE Regulations same, for a marginal increase in understanding deficiency of ETFs Trading Strategies, deficiency in investors' knowledge is increases by 0.271 .

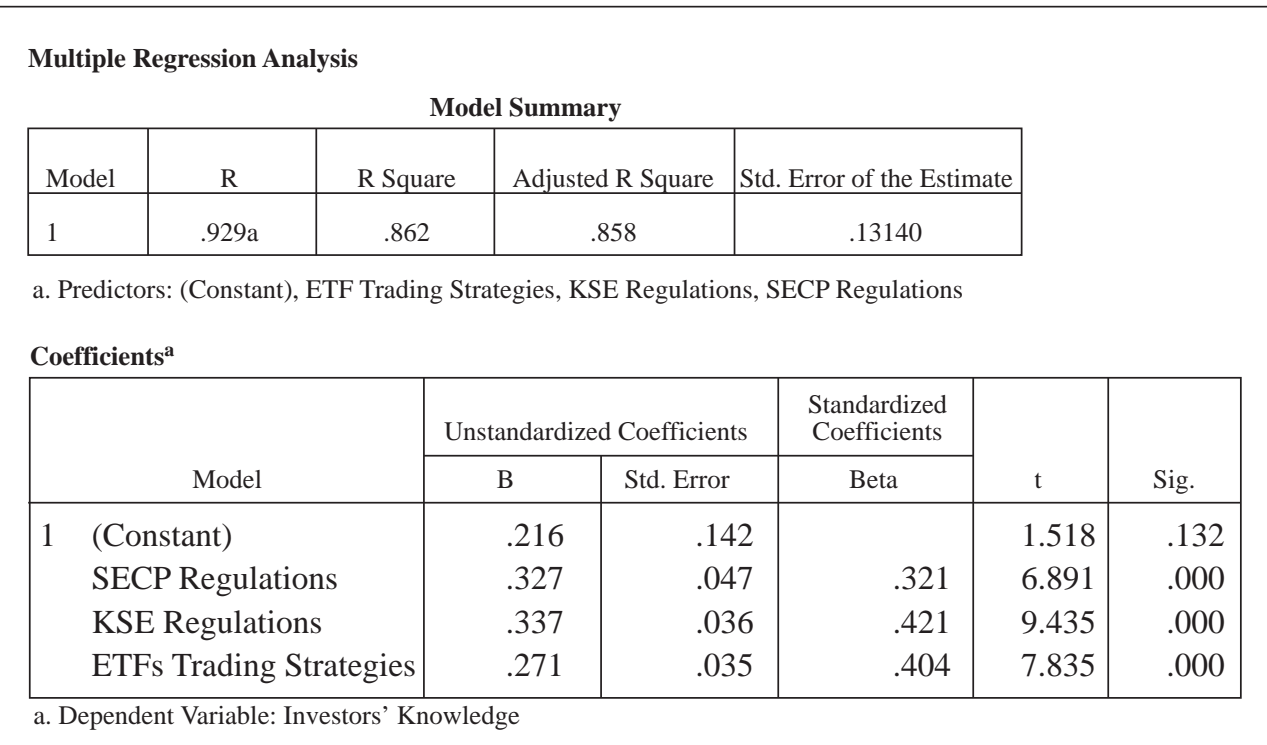

\begin{tabular}{l|llll}
\hline 78 & Jaunary - June 2013 & Volume 11 & Number 1 & JISR-MSSE
\end{tabular}




\section{Conclusion}

Mean response to all examined variables was more than 3 led us to the understanding that all participants were somehow agreed with identified variables. Among factors of (SECP Regulations, KSE Regulations and ETFs Trading Strategies) on average the factor of ETFs Trading Strategies with the mean response of 3.34 moving towards "Agree" means more expose to attention that authorized participants or investors at KSE has to consistently develop and improve the existing level of knowledge. Consistency levels of knowledge deficiencies in all variables (i.e. Investors' knowledge, SECP Regulations, KSE Regulations and ETFs Trading Strategies) have 10.53\%, 10.37\%, 13.21\% and $15.56 \%$ coefficients of variations respectively. This shows that participants' responses were more consistent about the deficiency in understanding SECP regulations. Spearman's correlation coefficient for knowledge deficiency in SECP regulations with $r=0.547$ and $p$ value is less than 0.05 at $5 \%$ significance level which is statistically significant, deficiency in KSE regulation with $r=0.533$ and $p$ value is less than 0.05 which is also significant at $5 \%$ level of significance. Similiarly, knowledge deficiency in understanding ETFs Trading Strategies with $r=0.536$ is also significant at 5\% level of significance. Hypotheses lead to the conclusion that their exist evidence that investors knowledge is influenced by SECP regulations, KSE regulations and ETFs Trading Strategies.

\subsection{Recommendations}

SECP should take initiative to improve investor's knowledge by conducting seminars. Management of Karachi Stock Exchange should create insights to investors promoting ETFs as financial product and a tool to hedge and diversify risk associated with portfolio investments. Asset Management Companies should issue ETFs global trends and tendencies, in the context of new strategies as a part of their weekly, daily and other relevant research reports. Asset Management Companies should also make available online tutorials and webinar about the functions, creation, and redemption processes in the context of local regulations. In future researchers can add more variables, and increase sample size with empirical evidences to reduce multi-collinearity

\section{References}

Ananth, M. (2012). Exchange-Traded Funds, Market Structure, and the Flash Crash. Financial Analysts Journal, 68 (4), 20-35.

BlackRock, R.( 2011). ETF Landscape - Hand Boo, 1st edition. United Kingdom: BlackRock Publishers UK.

Bruce, C. , Greig, K.,Martin Fridson, S. (2011). Empirical Evidence from ETF. Financial Analysts Journal, 67(3), 4-20.

Dellva, W. L. (2001). Exchange-Traded Funds Not for Everyone, Journal of Financial Planning, 14(1), 110-124.

Deutsche, B. (2012) . MSCI Pakistan IM TRN Index ETF. [www] Extchange Traded Fund Data Base UK. Available from: http://www.etf.db.com/HK/EN/showpage.asp?pageid=132\&blauswahl=1 [ Accessed on August 25, 2012] 
Fonder, T. (2013). Tundra pakistanfond, Class A, SEK: Regulation Comparison. Available from: http://www.tundrafonder.se/wp-content/uploads/2013/06/TUNDRA-PakistanKIID-Regul-SECP-English-2013-05-31.pdf Retrieved November 14, 2013

Gary, L. G. (2003). Protecting Fund Shareholders from Costly Share Trading. Financial Analysts Journal, 60(3), 22-32.

Gauhar, M. (2013). Exchange Traded Funds in Pakistan. Available from: http://bluechipmag.com/etf Retrieved November 22, 2013.

Goetzmann, W. (2001). Day Trading International Mutual Funds: Evidence and Policy Solutions. Journal of Financial and Quantitative Analysis, 36(3), 287-309.

Ishare (2013). Ishare Quarterly Reports. Available from https:// http://us.ishares.com/product_info/fund Accessed on November 15, 2013

Jeeman, J. (2005). Samuelson's Dictum and the Stock Market for ETFs. Economic Inquiry, $43,221-228$.

KSE. (2013). Regulations Governing Market Makers of The Karachi Stock Exchange (Guarantee) Limited. Available from:

http://www.kse.com.pk/.../communicator.php?...regulations_Governning ETF_12/Mktmaker.pdf Retrieved November 18, 2013

Mark, S., Roberto, R. (2011). Principal Components as a Measure of Systemic Risk in ETFs. Journal of Portfolio Management, 37, 102-114.

Pauline, M., Jisok, K. (2013). Leveraged and inverse ETF performance during the financial crisis. Journal of Managerial Finance, 39, 476-508.

Rizvi, K. (2013). Exchange of Trust for ETFs. Blue Chip Magazine, 9, 72-75.

SECP. (2013). Minimum Requirement for Managing ETF for AMC, [www] Securities and Exchange Commission of Pakistan Available from: http://www.secp.gov.pk/circulars/pdf/Cir_2012/Cir15.pdf Retrieved November 16, 2013.

Stoyu, I., Ivanov. (2013). High-frequency analysis of exchange traded funds' pricing deviation. Journal of Managerial Finance, 39, 509-524.

Strauss, J. \& Stuart, M. (2000). Exchange traded funds-the wave of the future, The Investment Lawyer, 7(1),15-21.

Vanguard, A. M. (2012). Vanguard ETF Guide. [www] Vanguard Asset Mangement Company. Available from https://www.vanguard.co.uk/documents/adv/literature/etfs-adviserguide.pdf [Accessed on August 25, 2012, ]

Ziglar, B. (2002). ETFs finish in first place. Journal of Financial Planning, 47(2), 82-85.

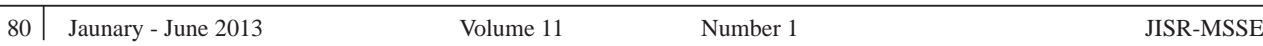




\section{Appendix}

Table 1: Cornbach's Alpha Reliability Test

Reliability Statistics

\begin{tabular}{|c|c|}
\hline $\begin{array}{c}\text { Cronbach's } \\
\text { Alpha }\end{array}$ & N of Items \\
\hline .850 & 4 \\
\hline
\end{tabular}

Table 2: Descriptive Analysis

\begin{tabular}{|c|c|c|c|c|}
\hline Statistic & SECP Regulations & KSE Regulations & ETFs Trading Strategies & $\begin{array}{c}\text { Investors' } \\
\text { Knowledge }\end{array}$ \\
\hline Mean & 3.29 & 3.30 & 3.34 & 3.31 \\
\hline Median & 3.20 & 3.20 & 3.20 & 3.20 \\
\hline Mode & 3 & 3 & 3 & 3 \\
\hline Standard Deviation & 0.3417 & 0.4353 & 0.5193 & 0.3484 \\
\hline Variance & 0.1167 & 0.1895 & 0.2697 & 0.1214 \\
\hline $\begin{array}{c}\text { Coefficient of } \\
\text { Variation }\end{array}$ & $10.37 \%$ & $13.21 \%$ & $15.56 \%$ & $10.53 \%$ \\
\hline
\end{tabular}

Table 3: Distribution Analysis

\begin{tabular}{|l|c|c|c|c|}
\hline \multicolumn{1}{|c|}{ Statistic } & $\begin{array}{c}\text { Investors' } \\
\text { Knowledge }\end{array}$ & $\begin{array}{c}\text { SECP } \\
\text { Regulations }\end{array}$ & $\begin{array}{c}\text { KSE } \\
\text { Regulations }\end{array}$ & $\begin{array}{c}\text { ETFs Trading } \\
\text { Strategies }\end{array}$ \\
\hline Mean & 3.30236 & 3.28485 & 3.29091 & 3.33333 \\
\hline Standard Error & 0.03483 & 0.03325 & 0.04367 & 0.05224 \\
\hline Standard Deviation & 0.34658 & 0.33085 & 0.43450 & 0.51981 \\
\hline Sample Variance & 0.12012 & 0.10946 & 0.18879 & 0.27020 \\
\hline Kurtosis & 3.64702 & 0.21323 & 6.68037 & 4.69382 \\
\hline Skewness & 1.91916 & 0.88138 & 2.23541 & 2.27229 \\
\hline Range & 1.80000 & 1.40000 & 2.20000 & 2.40000 \\
\hline Minimum & 2.80000 & 2.80000 & 2.80000 & 2.80000 \\
\hline Maximum & 4.60000 & 4.20000 & 5.00000 & 5.20000 \\
\hline Sum & 326.93333 & 325.20000 & 325.80000 & 330.00000 \\
\hline Count & 99.00000 & 99.00000 & 99.00000 & 99.00000 \\
\hline
\end{tabular}


Table 4: Correlations

\begin{tabular}{|c|c|c|c|c|c|c|}
\hline & & & \begin{tabular}{|l} 
Investors' \\
Knowledge
\end{tabular} & $\begin{array}{l}\text { SECP } \\
\text { Regulations }\end{array}$ & $\begin{array}{l}\text { KSE } \\
\text { Regulations }\end{array}$ & $\begin{array}{l}\text { ETFs Trading } \\
\text { Strategies }\end{array}$ \\
\hline \multirow[t]{4}{*}{ Spearman's rho } & $\begin{array}{l}\text { Investors' } \\
\text { Knowledge }\end{array}$ & $\begin{array}{l}\text { Correlation } \\
\text { Coefficient } \\
\text { Sig. (2-tailed) } \\
\text { N }\end{array}$ & $\begin{array}{l}1.000 \\
100\end{array}$ & $\begin{array}{l}.547 * * \\
.000 \\
100\end{array}$ & $\begin{array}{l}.533 * * \\
.000 \\
100\end{array}$ & $\begin{array}{l}.536^{* *} \\
.000 \\
100\end{array}$ \\
\hline & SECP Regulations & $\begin{array}{l}\text { Correlation } \\
\text { Coefficient } \\
\text { Sig. (2-tailed) } \\
\mathrm{N}\end{array}$ & $\begin{array}{l}.547 * * \\
\\
.000 \\
100 \\
\end{array}$ & $\begin{array}{l}1.000 \\
. \\
100 \\
\end{array}$ & $\begin{array}{l}.105 \\
.300 \\
100 \\
\end{array}$ & $\begin{array}{l}.497 * * \\
\\
.000 \\
100 \\
\end{array}$ \\
\hline & KSE Regulations & $\begin{array}{l}\text { Correlation } \\
\text { Coefficient } \\
\text { Sig. (2-tailed) } \\
\mathrm{N}\end{array}$ & $\begin{array}{l}.533^{* *} \\
.000 \\
100 \\
\end{array}$ & $\begin{array}{l}.105 \\
.300 \\
100 \\
\end{array}$ & $\begin{array}{l}1.000 \\
. \\
100 \\
\end{array}$ & $\begin{array}{l}.216^{*} \\
.031 \\
100 \\
\end{array}$ \\
\hline & $\begin{array}{l}\text { ETFs Trading } \\
\text { Strategies }\end{array}$ & $\begin{array}{l}\text { Correlation } \\
\text { Coefficient } \\
\text { Sig. (2-tailed) } \\
\text { N }\end{array}$ & $\begin{array}{l}.536^{* * *} \\
.000 \\
100\end{array}$ & $\begin{array}{l}.497 * * \\
.000 \\
100\end{array}$ & $\begin{array}{l}.216^{*} \\
.031 \\
100\end{array}$ & $\begin{array}{l}1.000 \\
100\end{array}$ \\
\hline
\end{tabular}

**. Correlation is significant at the 0.01 level (2-tailed).

$*$. Correlation is significant at the 0.05 level (2-tailed).

\section{Table 5: Inferential Analysis}

\begin{tabular}{|l|r|r|r|}
\hline Dependent Variable: Investors' Knowledge \\
\hline Outcomes & Hypothesis 1 & Hypothesis 2 & Hypothesis 3 \\
\hline R-Square & $47.90 \%$ & $54.40 \%$ & $65.70 \%$ \\
\hline Constant (a) & 0.97 & 1.355 & 1.492 \\
\hline SECP Regulations & 0.71 & - & - \\
\hline KESC Regulations & - & 0.593 & - \\
\hline ETFs Trading Strategies & - & - & 0.544 \\
\hline t-states & 9.596 & 10.903 & 13.713 \\
\hline Beta & 0.696 & 0.74 & 0.811 \\
\hline
\end{tabular}

